\title{
Traditional Material Resources versus Digital Resources: The Choice of Information Sources of the FCMS Nursing Interns
}

\author{
Rino S. de Sagun ${ }^{1}$, William D. Taala ${ }^{1}$, Filoteo B. Franco Jr. ${ }^{2}$, Rock P. Cordero ${ }^{1}$ \\ ${ }^{1}$ Fakeeh College for Medical Sciences, Jeddah, Saudi Arabia \\ ${ }^{2}$ Prince Mohammad Bin Salman College of Business and Entrepreneurship, King Abdullah Economic City, Thuwal, Saudi Arabia \\ Email: rsdesagun@fcms.edu.sa,wtaala@fcms.edu.sa,ffranco@mbsc.edu.sa,rcordero@fcms.edu.sa
}

How to cite this paper: de Sagun, R. S., Taala, W. D., Franco Jr., F. B., \& Cordero, R. P. (2019). Traditional Material Resources versus Digital Resources: The Choice of Information Sources of the FCMS Nursing Interns. Creative Education, 10, 667-676.

https://doi.org/10.4236/ce.2019.104049

Received: March 13, 2019

Accepted: April 14, 2019

Published: April 17, 2019

Copyright $\odot 2019$ by author(s) and Scientific Research Publishing Inc. This work is licensed under the Creative Commons Attribution International License (CC BY 4.0).

http://creativecommons.org/licenses/by/4.0/

(C) (i) Open Access

\begin{abstract}
This paper seeks to determine the choice of information source among FCMS nursing interns using the three-dimensional evaluation method namely; reliability, accessibly and purpose between the traditional and digital resources. Appropriate cross tabulations were used in the study to present the results using actual numbers, percentages and means. The results showed that there is no significant difference on the perception among respondents with regard to reliability, accessibility and purpose of the traditional and digital sources of information albeit that digital resource has just been recently introduced in the kingdom. Furthermore, the study also presented the respondent's perception on the relationship of the two sources of information, specifically books and the Internet. The respondents mostly answered "highly accepted" as indicated by the high averages with a mean score nearly 5 .
\end{abstract}

\section{Keywords}

Information Sources, Traditional Information Sources, Digital Resources

\section{Introduction}

We live in an information age where the amount of information available is so incredibly large that we cannot know everything about it. Similarly, the available information available today, is not only a massive, but also an unequal level of quality. You should not only possess the skills needed on where you find information but as well as which of these informations you should accept. You may feel overwhelmed with the extremities of the information and may be tempted to accept what you find. It is necessary to evaluate the information effectively 
all the time so as not to be tempted according to Tan, W.-K., Tan, C.-H. and Teo, H.-H. (2012). The key to the success of this digital medium is its ability to support the exchange of information regarding face-to-face communication.

The role of books and libraries cannot be ignored. Books and libraries serve as nodes that connect all learning environments, whether formal or informal. With global information and knowledge resources, books and libraries, therefore, can play a fundamental role in the development of future lifelong learning systems. Parents emphasize the books in their desire for their children to be more informed, more informed and more productive in their community and their contribution in their progress according to Al Harbat, R. and Al Saqarat, K. (2017).

The development of information and communication technologies (ICT) has laid the foundations for the creation of information networks, offering users even a small local access to information resources around the world. Over time, with the improvement of technologies, learning methods have evolved. Since the inception of the Internet and learning the World Wide Web, they have acquired new forms. Correspondence could now be carried out more easily than ever with communication methods. Dittmar, E., and McCracken, H. (2012) state that by providing tools to facilitate high-quality communication, faculty members are challenged and inspired to maximize student success and motivated to continue to develop and support teaching skills based on individual and collective feedback. Email has quickly replaced telephone conversations and websites allow users to view materials in a simple and inexpensive manner, largely denying the need to receive printed information by mail. Other methods of communication used include chat between students and tutors, viewing conferences and videoconferences in real time.

\subsection{Traditional Versus Modern Information Sources}

Traditional Resource materials are reading materials which are written or printed. Examples of such are magazines, newspapers, journals, books, diaries, encyclopedias, and other written or printed documents. Back in the past (the early 1980's to be particular), these are the common materials used by instructors. These are the materials proved to have much historical importance and provided more memory and depth. Printed materials also proved to be more factual, when these materials are used in court hearings, these materials are said to have more weight.

Computer information on the other hand, can readily give the information, saving the instructor's effort to type the gathered information again by copy and paste method. However, instructors tend to become laxer and chances to plagiarize become more prominent and digital resources could not only flow between institution as across continents too (Marušić, 2015).

Computer-Generated Data is digitally mastered information. This information is gathered from the Internet and other software which provides digitally 
encoded data.

Nursing interns use the Internet, since it gives the information needed in a much faster way, in a click of a button, they can already get the information they are searching for. In addition to this, the WWW can provide the researcher with graphics or needed diagrams that will enhance their work.

\subsection{Notable Scientific Ideas about Traditional and Digital Resources}

The existences of advance technology are helpful because reports that usually take a week to prepare can now be done in a day or less. Tasks usually delegated to a group can now be done in one day or less by a single person. Mathematical computations used to take four years to finish can now be run without anybody tending to it.

In the Pew Internet Project Report (Pew Research Center, 2003), an overwhelming number of university students reported that the Internet, instead of the library, is the main site of their information searches because the Internet is likely to be trying to trust this in the search of academic resources. As trusted users and experts in computing resources, university students appreciate access to accurate and up-to-date information with easily identifiable authors.

Students are increasingly independent in their research habits, rely on librarians to get help and, instead, use familiar sources, such as Internet search engines (Pew Research Center, 2003).

An interesting study on the use of the Internet by students was revealed in a study by Korgen, Odell and Schumacher (2001), published in the Electronic Journal of Sociology. The study conducted in the United States found that even students who spent more hours per week studying spent more time online than those who spent less time on academic work.

An interesting study conducted by Dr. Marcia J. Belcheir (1998), presented at the Rocky Mountain Association for Institutional Research, revealed an interesting view of age and gender differences in educational preferences. This study asked whether the age and/or gender of the students have an impact on the preferences of 38 teaching practices designed to improve learning and preparation for college and university achievement. Within the educational preferences, a general Analysis of variance test showed significant differences in age but not in sex. The follow-up tests showed significant results for only four elements: using humor, providing study guides for reading, requesting presence and using a variety of visual elements in lesson situations. With the exception of requesting assistance, younger students showed a greater preference for these teaching practices than older students. The study further explained that, students showed few differences in their perceptions of the ability to handle the intellectual, emotional, and organizational demands of college.

Another paper by Dr. David Passig and Haya Levin (2000) showed the interaction between gender, age, and multimedia interface design. The study examined whether differences among boys and girls in the different age groups on 
time on task and on intrinsic satisfaction, are differentially associated to educational interfaces. The findings regarding time on task and intrinsic satisfaction indicate significant differences with multimedia learning interfaces among boys and girls in the different age groups.

In 1962, the theory of Ausubel (1962) refers to the way in which people learn large amounts of meaningful material from verbal or textual presentations in a school environment. According to Ausubel, learning is based on the types of processes, representations and superior combiners that occur during the reception of information. A primary process in learning is subsumption in which the new material is related to ideas relevant to the existing cognitive structure on a substantial, not literal, basis. Cognitive structures represent the residue of all learning experiences; Oblivion occurs because some details are integrated and lose their individual identity.

Reigeluth's (1992) theory of elaboration argued that technology education should be organized from simple to complex to increase learning, providing the student with a meaningful context in which to integrate later ideas. The theory has seven strategic components: a processing sequence, prerequisite learning sequences, synthesis, synthesis, analogies, cognitive strategies and student control. The theory has implications in the design of instructions and the curriculum in which the work of Ausubel and Bruner provided the basis for the theory of elaboration.

Bill Daley explained about the article published in Computers Are Your Future (Daley \& Daley, 2005); imagine a source of information containing billions of documents, each of which can be accessed almost instantly through the computer on your disk. And also imagine that this source of information is growing at an amazing rate, with thousands of new documents appearing every day.

In Saudi Arabia, all information must conform to the Islamic teachings and non-derogatory to the traditions and culture of the society, that is spite it was only on 2010 that digital information was institutionalized through the creation of Saudi Digital Library (SDL), a government sponsored consortium databases that features several reputable publishers, a promising usage was seen and evident all throughout the societies and not only the academic world, as such this study was conceptualized.

\section{Methodology}

This study was conducted to provide additional information, create awareness, and consciousness on the traditional information materials and digital resources among the FCMS nursing interns. A questionnaire was designed using the three-dimensional evaluation method of information sources such as reliability, accessibility and purpose and was subjected to Cronbach's alpha test with a result of 0.833 reliability. The 5 -point Likert's system was utilized for the computation of the responses of the respondents and will be treated using appropriate statistical tools. 


\section{Findings and Discussions}

\subsection{On the Number of Hours They Read}

Table 1. Number of hours the respondents used books and the internet to do their research in a month.

\begin{tabular}{ccccc}
\hline \multirow{2}{*}{ Number of Hours } & \multicolumn{2}{c}{ Traditional Resources } & \multicolumn{2}{c}{ Digital Resources } \\
\cline { 2 - 5 } & F & $\%$ & F & $\%$ \\
\hline $1-5$ Hours & 2 & 7.6 & 2 & 7.6 \\
6 - 10 Hours & 3 & 11.5 & 8 & 30.76 \\
10 or More Hours & 5 & 19.23 & 6 & 23.07 \\
\hline
\end{tabular}

Table 1 shows the study, the respondents were asked about how many hours they referred to traditional information sources and the digital resources for their lectures and researches. About 19.23 percent of the respondents claimed that they usually used reference books for more than ten hours in a month whenever they need updates for their lectures and in doing their research studies. While those using the digital resources for more than ten hours in a month for their reference materials totaled 6 or 23.07 percent of the total respondents. Eight respondents (30.76\%) used the digital resources for 6 to 10 hours in a month. And about 11.5 percent of the respondents consumed 6 to 10 hours in a month reading traditional books for their reference materials. There were only two respondents who consulted a book or the internet for less than five hours.

\subsection{On Their Perception of the Reliability of the Traditional Information Sources}

Table 2. Mean scores on the perception of respondents on the reliability of information contained in books by reliability measure and by gender.

\begin{tabular}{|c|c|c|c|c|c|c|}
\hline Reliability Measure & Both Sexes & VI & Male & VI & Female & VI \\
\hline Overall Average & 4.82 & VMA & 4.86 & VMA & 4.81 & VMA \\
\hline $\begin{array}{l}\text { 1) The sources go through an extensive } \\
\text { publication process that includes the } \\
\text { review and revision of articles. The } \\
\text { process has drafts of facts, multiple } \\
\text { reviewers and editors to guarantee the } \\
\text { quality of the publication. }\end{array}$ & 4.88 & VMA & 4.93 & VMA & 4.87 & VMA \\
\hline $\begin{array}{l}\text { 2) The sources clearly indicate who } \\
\text { the author is, to which organization } \\
\text { he is affiliated and when his work } \\
\text { was published. }\end{array}$ & 4.87 & VMA & 4.93 & VMA & 4.86 & VMA \\
\hline $\begin{array}{l}\text { 3) External sources of information } \\
\text { and direct quotes are clearly marked } \\
\text { and identified. }\end{array}$ & 4.85 & VMA & 4.93 & VMA & 4.83 & VMA \\
\hline $\begin{array}{l}\text { 4) There are prejudices and } \\
\text { special interests. }\end{array}$ & 4.60 & VMA & 4.64 & VMA & 4.59 & VMA \\
\hline $\begin{array}{l}\text { 5) It is likely that only qualified } \\
\text { authors have their manuscripts } \\
\text { accepted for publication. }\end{array}$ & 4.82 & VMA & 4.86 & VMA & 4.82 & VMA \\
\hline
\end{tabular}




\section{Continued}

6) The publication information, such as

the publication date, the editor, the

author and the editor, is always

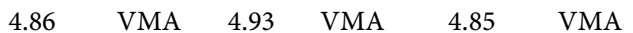

clearly included in the publications.

$\begin{array}{lllllll}\text { 7) The coverage of the topic is complete. } & 4.84 & \text { VMA } & 4.79 & \text { VMA } & 4.85 & \text { VMA }\end{array}$

Note: VI-Verbal Interpretation, VMA-Very much accepted, FA—Fully accepted.

Based on the results shown in Table 2 with regard to the mean score of respondents regarding their perception on the reliability of information contained in traditional sources, the respondents had perceived books as a very much accepted source of information as indicated by the overall mean of 4.82 which is nearly 5.0. Furthermore, they perceived books as a highly reliable reference whenever they need one.

By gender, male respondents had a higher average than females with 4.86 and 4.81 , respectively. In terms of the reliability measures, the highest average was recorded under sources go through an extensive publication process that includes editing and article review to ensure the quality of publication with 4.88 . The next highest mean of 4.87 was sources clearly indicate who the author is, author's affiliation and the date of publication. It was noted that the averages were very close to each other and statistically speaking it seems that there is not much difference on the averages. However, this will be further studied in the later part of this chapter using hypothesis testing.

\subsection{On Their Perception of the Reliability of the Digital Information Sources}

Table 3. Mean scores on the perception of respondents on the reliability of information contained in books by reliability measure and by gender.

\begin{tabular}{cccccccc}
\hline Reliability Measure & Both Sexes & VI & Male & VI & Female & VI \\
\hline Overall Average & 4.80 & VMA & 4.81 & VMA & 4.80 & VMA
\end{tabular}

1) The sources go through an extensive publication process that includes the review and revision of articles. The process has drafts of facts, multiple

$\begin{array}{llllll}4.84 & \text { VMA } & 4.79 & \text { VMA } & 4.85 & \text { VMA }\end{array}$
reviewers and editors to guarantee the quality of the publication.

2) The sources clearly indicate who the author is, to which organization he is affiliated and when his work was

3) External sources of information and direct quotes are clearly 


\section{Continued}

5) It is likely that only qualified authors have their manuscripts accepted for $\begin{array}{lllll}4.82 & \text { VMA } & 4.79 & \text { VMA } & 4.83\end{array}$ VMA publication.

6) The publication information, such as the publication date, the editor, the author and the editor, is always clearly included in the publications.

$\begin{array}{llllllll}\text { 7) The coverage of the topic is complete. } & 4.84 & \text { VMA } & 4.79 & \text { VMA } & 4.85 & \text { VMA }\end{array}$

Note: VI-Verbal Interpretation, VMA-Very much accepted, FA—Fully accepted.

The mean scores of the respondents with regards to their perception on the reliability of the information featured in the digital resources were slightly lower than their opinion on the reliability of traditional as source of information as shown in Table 3. Overall, the average of 4.80 implies that they perceived the digital as a highly acceptable source of reliable information. They highly appreciated the use of the digital resources because it gives details on the name of the author, his/her affiliation and others; and proper quotations are clearly marked and emphasized. Both measures recorded a mean score of 4.86. In addition, the other measures namely, it indicates proper publication information like date of publication, author, publisher and others (4.85); articles go through editing procedures (4.84); coverage of the topic is complete (4.84) and authors were properly screened (4.82) were also given high scores by the respondents. Indication of biasness by the authors was also highly accepted by the respondents based on the mean score of 4.56. It means that even if sometimes authors were being biased in their opinions on the articles that they post on the internet it does not matter to the respondents and could still consider it a good resource material for their researches.

Male respondents very much accepted the fact that information or articles in the digital resources showed the name of the author/s and even observe proper quoting procedure whenever they use other people's opinions in their published material.

The mean score recorded for the two reliability measures was both 4.93 . On the other hand, female respondents scored 4.85 in both measure. Although the means scores of the male and female respondents indicated slight differences, the differences are not that significant.

\subsection{On Their Perception of the Accessibility of the Digital Information Sources}

Table 4. Mean scores on the perception of respondents with regard to the accessibility of using the traditional and the digital resources as source of information by gender.

\begin{tabular}{lcccccc}
\hline \multicolumn{1}{c}{ Accessibility Measure } & $\begin{array}{c}\text { Both } \\
\text { Sexes }\end{array}$ & VI & Male & VI & Female & VI \\
\hline Traditional Resources Overall Mean & $\mathbf{4 . 0 4}$ & FA & $\mathbf{4 . 2 0}$ & FA & $\mathbf{4 . 0 0}$ & FA \\
1) Available almost anywhere. & 4.12 & FA & 4.14 & FA & 4.11 & FA \\
\hline
\end{tabular}




\section{Continued}

\begin{tabular}{|c|c|c|c|c|c|c|}
\hline 2) Topics/subject matter easy to locate. & 4.14 & FA & 4.36 & VMA & 4.10 & FA \\
\hline 3) Global & 4.16 & FA & 4.36 & VMA & 4.13 & FA \\
\hline 4) Hard referencing & 3.72 & FA & 3.93 & FA & 3.68 & FA \\
\hline Digital Resources Overall mean & 4.17 & FA & 4.14 & FA & 4.17 & FA \\
\hline 1) Available almost anywhere. & 4.21 & VMA & 3.86 & FA & 4.28 & VMA \\
\hline 2) Topics/subject matter easy to locate. & 4.33 & VMA & 4.36 & VMA & 4.32 & VMA \\
\hline 3) Global & 4.31 & VMA & 4.36 & VMA & 4.30 & VMA \\
\hline 4) Hard referencing & 3.82 & FA & 4.00 & FA & 3.79 & FA \\
\hline
\end{tabular}

Note: VI-Verbal Interpretation, VMA — Very much accepted, FA-Fully accepted.

The mean scores on the perception of respondents regarding the accessibility of the two sources of information were presented in Table 4. The respondents had fully accepted the fact that both sources are easily accessible as shown by their overall mean of 4.04 and 4.17 for books and internet, respectively. The use of the internet as source of information had a slightly higher average than the use of books. This could mean that the respondents viewed that the internet is accessible anywhere even in the wee hours of the morning as long as you have your computer and you can connect to the internet. While one can have access to books only if one goes to the library to do their research.

The use of the internet is perceived by respondents to be very much global (4.31), i.e., in the internet the information you can gather is limitless. It comes from different sources in the different parts of the world. If one uses a book the data that you get is limited to the contents of the books you use. In terms of "hard referencing," i.e. the researcher can have hard facts in a quick time, the respondents rated both sources as just fully acceptable based on their average rates of 3.72 (books) and 3.82 (internet). Male and female respondents posted slight differences in their averages with regard to the measures of accessibility for the traditional and modern sources of information. Their opinions did not vary enough to conclude of the existence of differences in their means.

\subsection{On Their Perception of the Purpose of Use between the Two Information Sources}

Table 5. Mean scores on the perception of respondents with regard to the purpose of use between the information sources.

\begin{tabular}{lcccc}
\hline Measure of Purpose & $\begin{array}{c}\text { Traditional } \\
\text { Sources }\end{array}$ & VI & $\begin{array}{c}\text { Digital } \\
\text { Resources }\end{array}$ & VI \\
\hline Overall Mean & 4.72 & VMA & 4.66 & VMA \\
1) Content is specific for intended audience & 4.72 & VMA & 4.71 & VMA \\
2) Content is easier to verify & 4.73 & VMA & 4.79 & VMA \\
3) Content is easier to understand. & 4.73 & VMA & 4.79 & VMA \\
\hline
\end{tabular}




\section{Continued}

\begin{tabular}{llccc}
\hline 4) Business is to inform and educate. & 4.73 & VMA & 4.79 & VMA \\
5) Business is more of entertainment. & 4.84 & VMA & 4.64 & VMA \\
6) Business is communication. & 4.72 & VMA & 4.64 & VMA \\
7) Anyone can publish anything he wants. & 4.68 & VMA & 4.50 & VMA \\
8) Quality control is difficult. & 4.65 & VMA & 4.43 & VMA \\
\hline
\end{tabular}

Note: VI-Verbal Interpretation, VMA-Very much accepted, FA-Fully accepted.

Table 5 shows the respondents very much accepted the fact that the purpose of the writers or authors in publishing information between the information sources could easily be perceived by the reader just by reading it based on the overall mean of 4.61 and 4.72 for the traditional and digital resources, respectively. In their opinion, if the writer wants to entertain, inform, educate etc. using their articles and other works of (writing) art their purpose is easily communicated to the reader (or it is easily understood by the reader). The average for each measure of purpose did not vary much but rather the averages are close to each other. Although the perceptions of both sources had slight differences, it is not that significant.

\section{Conclusion}

The results of the study showed that both respondents, i.e. males and females, highly accepted the relevance of the two sources in getting information for their school research studies. They had not perceived that one source is better than the other in terms of reliability of the source, its accessibility to the users and its purpose but they rather complement each other. They greatly accepted the fact that the two sources complement each other whenever there is a need to verify information from one source to the other source.

The results of the study showed that the use of both sources, i.e. traditional (like books) and digital sources (Internet), is essential whenever we need to do research. It is recommended that readers should use both sources whenever they need information. The two sources complement each other as choice of information and data. If you need to clarify information from one source, all you need to do is to validate it to the other source, that is, traditional to modern and vice versa.

\section{Conflicts of Interest}

The authors declare no conflicts of interest regarding the publication of this paper.

\section{References}

Al Harbat, R., \& Al Saqarat, K. (2017). The Role of Religious Institutions, Electronic Games, Books, and Educational Stories in the Development of the Child's Culture from the Perspective of Jordanian Mothers According to Some Variables. International Education Studies, 10, 141-151. 
http://sdl.edu.sa/middleware/Default.aspx?USESDL=true\&PublisherID=AllPublishers \&BookURL=https://sdl.idm.oclc.org/login?url=http://search.ebscohost.com/login.aspx ?direct=true \&db=eric\&AN=EJ1138589\&site=eds-live https://doi.org/10.5539/ies.v10n4p141

Ausubel, D. P. (1962). A Subsumption Theory of Meaningful Verbal Learning and Retention. The Journal of General Psychology, 66, 213-224. https://doi.org/10.1080/00221309.1962.9711837

Belcheir, M. J. (1998). Age and Gender Differences in Instructional Preferences. https://eric.ed.gov/?id=ED443358

Daley, B., \& Daley, W. (2005). Computers Are Your Future 2005. Upper Saddle River, NJ: Pearson Prentice Hall.

Dittmar, E., \& McCracken, H. (2012). Promoting Continuous Quality Improvement in Online Teaching: The Meta Model. Journal of Asynchronous Learning Networks, 16, 163-175.

http://sdl.edu.sa/middleware/Default.aspx?USESDL=true\&PublisherID=AllPublishers \&BookURL=https://sdl.idm.oclc.org/login?url=http://search.ebscohost.com/login.aspx ?direct $=$ true $\& \mathrm{db}=\mathrm{ehh} \& \mathrm{AN}=76476046 \&$ site $=$ eds-live

Korgen, K., Odell, P., \& Schumacher, P. (2001). Internet Use among College Students: Are There Differences by Race/ethnicity? Electronic Journal of Sociology. https://www.sociology.org/ejs-archives/vol005.003/korgen.html

Marušić, A. (2015). Publishing Scientific Journals in the Digital Age: Opportunities for Small Scholarly Journals. Prilozi, 35, 17-21.

http://sdl.edu.sa/middleware/Default.aspx?USESDL=true\&PublisherID=AllPublishers \&BookURL=https://sdl.idm.oclc.org/login?url=http://search.ebscohost.com/login.aspx ?direct=true $\& \mathrm{db}=$ asn $\& A N=101707461 \&$ site=eds-live https://doi.org/10.1515/prilozi-2015-0003

Passig, D., \& Levin, H. (2000). Gender Preferences for Multimedia Interfaces. Journal of Computer Assisted Learning, 16, 64-71. https://doi.org/10.1046/j.1365-2729.2000.00116.x

Pew Research Center (2003). The Internet and Campaign 2002. http://www.pewinternet.org/2003/01/05/the-internet-and-campaign-2002/

Reigeluth, C. M. (1992). Elaborating the Elaboration Theory. Educational Technology Research and Development, 40, 80-86. https://doi.org/10.1007/BF02296844

Tan, W.-K., Tan, C.-H., \& Teo, H.-H. (2012). Conveying Information Effectively in a Virtual World: Insights from Synthesized Task Closure and Media Richness. Journal of the American Society for Information Science \& Technology, 63, 1198-1212. https://doi.org/10.1002/asi.22600 